\title{
Osteonecrosis of the jaw (ONJ) in renal cell cancer patients after treatment including zoledronic acid or denosumab
}

\author{
Vittorio Fusco • Alberto Bedogni • Giuseppina Campisi
}

Received: 17 January 2014 / Accepted: 3 February 2014 /Published online: 26 February 2014

(C) Springer-Verlag Berlin Heidelberg 2014

Dear Editor,

The paper by Henry et al. published by Supportive Care in Cancer comparing efficacy of denosumab versus zoledronic acid in patients with bone metastases of advanced solid tumours [1] comes to integrate the original reports of three pivotal large randomized phase 3 trials [2-4], the publication by Saad et al. about osteonecrosis of the jaw (ONJ) in those three trials [5], and the combined outcome analysis by Lipton et al. [6].

Henry et al. [1] reported outcomes of the single trial conducted on patients with solid tumours (except breast or prostate cancers, object of other two trials) [2, 3], excluding patients with multiple myeloma: This ad hoc analysis confirmed the superiority of denosumab in delaying or preventing skeletal-related events [1]. Amongst side effects, after a median $(\mathrm{Q} 1, \mathrm{Q} 3)$ time on study of $6.7(3.2,13.0)$ and 6.4 (3.1, 12.9)months in the two groups, ONJ was reported in six denosumab arm patients $(0.8 \%)$ and in nine zoledronic acid arm patients $(1.1 \%)$.

We wish to underline some sparse data reported in the cited papers, focusing attention on occurrence of $\mathrm{ONJ}$ in patients with renal cell cancer (RCC) included in the trial.

In the summary ONJ analysis [5] of the above-mentioned three randomized trials comparing zoledronic acid and

V. Fusco $(\bowtie)$

Oncology Unit, SS Antonio e Biagio e Cesare Arrigo Hospital, Via Venezia 16, 15121 Alessandria, Italy

e-mail: vittoriofusco1@tin.it

A. Bedogni

Department of Surgery, Section of Oral and Maxillofacial Surgery, University and Hospital Trust of Verona, P.le L.A. Scuro 10, Verona 37134, Italy

G. Campisi

Department of Surgical, Oncological and Oral Sciences- Sector of Oral Medicine, Palermo University, Via del Vepro 129,

Palermo 90127, Italy denosumab in patients with several cancer types and conducted between 2006 and 2009, it appears that an "Oral Event Identified as Potential ONJ" was registered in 276 patients out of 5,723 (4.8\%). Finally, cases of positively adjudicated ONJ according to very strict criteria were only $89(1.6 \%)-37$ $(1.3 \%)$ on zoledronic acid and $52(1.8 \%)$ on denosumab. Notably, in the three trials, there were 14 ONJ cases among 464 patients treated with an antiresorptive agent (zoledronic acid or denosumab) and antiangiogenic agents (3.0\%) versus 75 ONJ cases among 5,259 patients receiving zoledronic acid or denosumab without any antiangiogenic agents (1.4\%) [5]: This kind of data seems to enforce recent literature data suggesting possible higher ONJ risk from combination of antiresorptive and antiangiogenic agents [7, 8].

According to the paper by Saad et al. [5], among 89 total adjudicated ONJ patients (treated either with zoledronic acid or denosumab) there were six RCC patients, out of a total number of enrolled RCC patients of $155[1,4]$. This $6 / 155$ (3.9\%) ONJ frequency in RCC patients is more than twice as high, if compared with the entire patient population (1.6\%).

In recent years, bone metastatic RCC patients received routinely targeted therapy, as monoclonal anti-VEGF antibody (bevacizumab), tyrosin-kinase inhibitors (sunitinib, sorafenib, pazopanib), mTOR inhibitors (temsirolimus, everolimus). Several types of recent reports suggest a relatively high ONJ risk in RCC patients after a combination of bisphosphonates (mostly zoledronic acid) and antiangiogenic agents (mostly sunitinib) [9-12].

The question is: could the antiangiogenic treatment have played a role in the $3.9 \% \mathrm{ONJ}$ rate among RCC patients in the trial illustrated by Henry et al.? Unfortunately, according to the reports of the trial $[1,4]$, it is neither arguable how many of those six RCC patients developing ONJ had received antiangiogenic agents, nor which bone antiresorptive agent was administered.

Furthermore, we can extrapolate from the cited reports of the trials [2-5] that, among 21 ONJ adjudicated cases, an antiangiogenic drug had been administered in six out of 
eleven ONJ patients in the zoledronic acid arm versus one out of ten ONJ patients in the denosumab arm. This seems to suggest a possible higher risk of ONJ in patients who had received zoledronic acid together with an antiangiogenic agent, in comparison to the association of denosumab with a targeted therapy.

We think that the details of the treatment received by RCC patients in the trial reported by Henry et al. [1, 4] (preferably if updated with longer follow-up) would be of value to clarify the role of a targeted therapy (i.e., antiangiogenic drugs) together with zoledronic acid or denosumab in developing ONJ.

\section{Disclosure/conflict of interest None.}

\section{References}

1. Henry D, Vadhan-Raj S, Hirsh V, von Moos R, Hungria V, Costa L, Woll PJ, Scagliotti G, Smith G, Feng A, Jun S, Dansey R, Yeh H (2014) Delaying skeletal-related events in a randomized phase 3 study of denosumab versus zoledronic acid in patients with advanced cancer: an analysis of data from patients with solid tumors. Support Care Cancer. 2013 Oct 26. [Epub ahead of print]

2. Stopeck AT, Lipton A, Body JJ, Steger GG, Tonkin K, De Boer RH, Lichinitser M, Fujiwara Y, Yardley DA, Viniegra M, Fan M, Jiang Q, Dansey R, Jun S, Braun A (2010) Denosumab compared with zoledronic acid for the treatment of bone metastases in patients with advanced breast cancer: a randomized, double-blind study. J Clin Oncol 28(35):5132-5139. doi:10.1200/JCO.2010.29.7101, Epub 2010

3. Fizazi K, Carducci M, Smith M, Damião R, Brown J, Karsh L, Milecki P, Shore N, Rader M, Wang H, Jiang Q, Tadros S, Dansey $\mathrm{R}$, Goessl C (2011) Denosumab versus zoledronic acid for treatment of bone metastases in men with castration-resistant prostate cancer: a randomised, double-blind study. Lancet 377:813-822

4. Henry DH, Costa L, Goldwasser F et al (2011) Randomized, doubleblind study of denosumab versus zoledronic acid in the treatment of bone metastases in patients with advanced cancer (excluding breast and prostate cancer) or multiple myeloma. J Clin Oncol 29:11251132

5. Saad F, Brown JE, Poznak CV et al (2012) Incidence, risk factors, and outcomes of osteonecrosis of the jaw: integrated analysis from three blinded active-controlled phase III trials in cancer patients with bone metastases. Ann Oncol 23:1341-1347

6. Lipton A, Fizazi K, Stopeck AT et al (2012) Superiority of denosumab to zoledronic acid for prevention of skeletal-related events: a combined analysis of 3 pivotal, randomised, phase 3 trials. Eur J Cancer 48:3082-3092

7. Troeltzsch M, Woodlock T, Kriegelstein S, Steiner T, Messlinger K, Troeltzsch M (2012) Physiology and pharmacology of nonbisphosphonate drugs implicated in osteonecrosis of the jaw. $\mathrm{J}$ Can Dent Assoc 78:c85

8. Lescaille G, Coudert AE, Baaroun V, Ostertag A, Charpentier E, Javelot MJ, Tolédo R, Goudot P, Azérad J, Ariane Berdal A, JeanPhilippe Spano JP, Ruhin B, Descroix V (2014) Clinical study evaluating the effect of bevacizumab on the severity of zoledronic acid-related osteonecrosis of the jaw in cancer patients. Bone 58:103107

9. Bozas G, Allgar V, Greenwood G, Maraveyas A, Osteonecrosis of the jaw in patients treated with sunitinib and zoledronic acid. (2011) ASCO Annual Meeting Abstract. J Clin Oncol 29: 2011 (suppl; abstr e15116)

10. Beuselinck B, Wolter P, Karadimou A, Elaidi R, Dumez H, Rogiers A, Van Cann T, Willems L, Body JJ, Berkers J, Van Poppel H, Lerut E, Debruyne P, Paridaens R, Schöffski P (2012) Concomitant oral tyrosine kinase inhibitors and bisphosphonates in advanced renal cell carcinoma with bone metastases. Br J Cancer 107(10):1665-1671. doi:10.1038/bjc.2012.385

11. Hansen PJ, Knitschke M, Draenert FG, Irle S, Neff A (2013) Incidence of bisphosphonate-related osteonecrosis of the jaws (BRONJ) in patients taking bisphosphonates for osteoporosis treatment - a grossly underestimated risk? Clin Oral Investig 17:1829 1837. doi:10.1007/s00784-012-0873-3

12. Fusco V, Porta C, Bedogni A, Saia G, Scoletta M, Bonacina R, Vescovi P, LoRe S, Campisi G (2013) Osteonecrosis of the jaw (ONJ) in patients with renal cell cancer (RCC) treated with bisphosphonates and sunitinib or other biological agents: characteristics of 39 cases in a multicenter survey. ECCO European Cancer Congress 2013 abstract. Eur J Cancer 49(suppl2):abs 1391 